\title{
THE PRESENCE OF FINE AND ULTRAFINE \\ PARTICULATE MATTER IN THE WORK ENVIRONMENT
}

\author{
Vladimír Adamec ${ }^{1}$, Klaudia Köbölová1, Michal Urbánek', Kristina Čabanová2, ${ }^{3}$, Vladimír Bencko ${ }^{4}$, Milan Tuček ${ }^{4}$ \\ ${ }^{1}$ Institute of Forensic Engineering, Brno University of Technology, Brno, Czech Republic \\ ${ }^{2}$ Faculty of Mining and Geology, VSB-Technical University of Ostrava, Ostrava, Czech Republic \\ ${ }^{3}$ Centre of Advanced and Innovative Technologies, VSB-Technical University of Ostrava, Ostrava, Czech Republic \\ ${ }^{4}$ Institute of Hygiene and Epidemiology, First Faculty of Medicine, Charles University and General University Hospital in Prague, Prague, \\ Czech Republic
}

\begin{abstract}
SUMMARY
This study presents the results of pilot measurement, where the exposure of fine and ultrafine particulate matter was monitored. The measurement was performed in welding workplace, where these particles are produced unintentionally. The measurement consisted of collecting information and measuring the concentration of particles in the workplace, where data collection was focused only on inhalation exposure. During welding, primarily $300 \mathrm{~nm}$ size particles are produced, and their concentration is strongly influenced by the welding material, type of welding and suction. The particles are amorphous in terms of morphology and contain manganese, iron and silicon, which can cause neurodegenerative diseases. Furthermore, the results indicate the importance of monitoring oral exposure.
\end{abstract}

Key words: work environment, fine and ultrafine particulate matter, risk assessment, health

Address for correspondence: K. Köbölová, Institute of Forensic Engineering, Brno University of Technology, Purkyňova 464/118, 61200 Brno, Czech Republic. E-mail: xckobolova@usi.vutbr.cz

https://doi.org/10.21101/cejph.a6174

\section{INTRODUCTION}

Fine $\left(\mathrm{PM}_{2.5}\right)$ and ultrafine $\left(\mathrm{PM}_{0.1}\right)$ particulate matters are part of human life. They have always been on Earth, especially in a natural form, for example from volcanic eruptions. With the development of human society their origin and concentration began to change, and people started to use them for example in the glass industry or civil engineering. Especially in the recent years there has been a rapid development of nanotechnologies and their application in medicine, industry, power engineering etc.

The main area of interest is the potential unacceptable impact of these particles on workers, as they are the first to be exposed to the potential risks. It is necessary to set safety and health criteria at work that define the responsible development of nanotechnologies. Schulte et al. (1) presents five critical actions that should make a decisive impact on responsible development. These include the identification and monitoring of hazardous particles in the workplace, assess exposure and report potential hazards to workers, manage risks to safety and health at work, and support the safe development of nanotechnology.

In relation to work environment (2) we can divide the origin of nanoparticles and $\mathrm{PM}_{0.1}$ into 3 basic groups according to the process of origin:

- processes in which particles/materials are intentionally produced (so called engineered materials);

- processes related to the use of nanomaterials;
- processes where particles are created as a by-product (welding, grinding, combustion processes, melting or refining of metal etc.).

In connection with the rapid development of technologies more and more focus is placed on research into the effects of nanoparticles on human health. The toxic effect of inhaled nanoparticles has been proven many times in the last years, however, there is still discussion concerning the exact mechanism of this impact on living organisms (3-5). Also, problematic situation is intensified by the fact that currently there is a lack of legislation focused on the nanomaterial safety (use, work with nanomaterials, etc.) and reduction of related risks that accompany them throughout their life cycle. The latest update at European Union level was made at the beginning of 2019, when in the first quarter of 2020 the Annex XVII to the Registration, Evaluation, Authorisation and Restriction of Chemicals (REACH) will come into force (first half of 2020). These updates focus on the evaluation and assessment of selected nanomaterials. There are numerous recommendations available on the occupational health and safety of nanomaterials from the institutions worldwide, but it is still not enough. Current absence of these regulations is mainly due to the problematic approach to their assessment, high diversity of the nanomaterials forms and also the financial demands (6).

The highest concentrations of nanoparticles are usually recorded in facilities where metals are treated under very high temperatures such as iron and steel works or welding shops (7). In these facilities the concentrations recorded are up to a hundred 
times higher compared with the surrounding atmosphere. Working in such environment poses a significant health risk for the staff. People working in facilities using or producing nanomaterials which contain industrially produced nanoparticles may even be exposed to a higher risk (8).

In the present work, the exposure to the welding dust in workplace was estimated. Multiple measurement metrics (e.g., concentration, size distribution, morphology, and elemental analysis) of welding particles were combined to assess exposure of workers. This study constitutes a set of basic data for a development of methods for measuring exposure in workplace.

\section{MATERIALS AND METHODS}

For monitoring nanoparticles in atmosphere of the working environment were selected working processes, where these particles are created unintentionally. In this measurement, the welding process was monitored, where the worker is exposed daily. Metal Active Gas (MAG) - $\mathrm{CO}_{2}$ shielding gas welding was used in these operations. Four mobile devices were used in this study to measure concentrations of fine and ultrafine particles in the air, namely the Condensation Particle Counter (TSI CPC 3007), TSI AM520 SidePak, Optical Particle Sampler (TSI OPS 3330), and AirChek Touch (SKC, Inc.).

The CPC operates on the principle of particle condensation counting, which allows high measurement accuracy over the particle size range of $10-1,000 \mathrm{~nm}$. The SidePak is a personal aerosol meter. It uses photometry to determine the mass concentration of particles in the atmosphere. The basic instrument range is 100$10,000 \mathrm{~nm}$. The OPS works on a principle of optical spectrometry, it measures not only the concentration but also the number of particles. The total range of this instrument is $300-10,000 \mathrm{~nm}$. The Airchek Touch does not belong to the measuring instruments category, but to the sampling devices. It is a sampling pump with adjustable air flow, which is connected to the sampling cassette. A round-shaped polycarbonate filter (diameter $37 \mathrm{~mm}$, porosity $400 \mathrm{~nm}$ ) was placed in the cassette, which collects particles during measurement. Thanks to the overlap of the fraction range it is possible to compare the results from individual instruments with each other.

The workplace size was $5 \times 6 \mathrm{~m}$, where 2 stations were separated by movable wall. In stations 1-1 worker grinded and welded. The workplace was equipped with air condition, special ventilation. The workers had personal equipment such as gloves and welding mask. The instruments (Fig. 1a) were placed at a distance of approximately $1.5 \mathrm{~m}$ from the welder's work area, for the reason of the risk of equipment damage and also for the reason of the possibility for the employee performing the work activity (without restrictive conditions). Sampling of air particles was performed in parallel, where were two AirChek Touch instruments available for particles sampling. One was placed in the area behind worker and the second one was attached to the worker's protective clothing. The sampling probe with the sampling cassette was led to the working's breathing zone (up to approximately $30 \mathrm{~cm}$ from the mouth and nose) (Fig. 1b). At the same time, samples of worker's saliva were taken before and after measurement interval. Saliva was collected into autoclavable centrifuge microtubes Eppendorftype $(5 \mathrm{ml})$. Prior to the start of the measuring activity, the instruments were calibrated in accordance with the requirements of the manufacturers. The measurement was started before employers began the work process, when they were preparing welding, then continuously until the first pause and then an hour after the end of work shift. During the measurement, the filters in the sampling cassettes were replaced after an hour and a half because of the risk of their possibility of clogging and subsequent malfunction of the sampling pumps (AirChek Touch). The measured data were exported from the devices to the computer and evaluated, where the graphs evaluating the concentration and distribution of particles over time were constructed from the measured data, taking into account the individual events that occurred during the measurement (e.g. break, technology change). Collected samples per filter were analysed by scanning electron microscope (SEM MIRA3, Tescan) using elemental analysis energy dispersive Xray analysis (EDX). a)

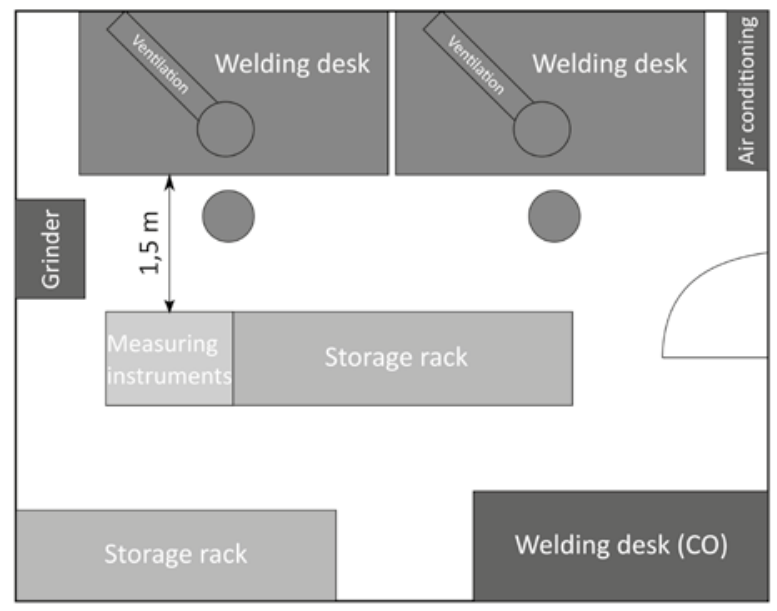

b)

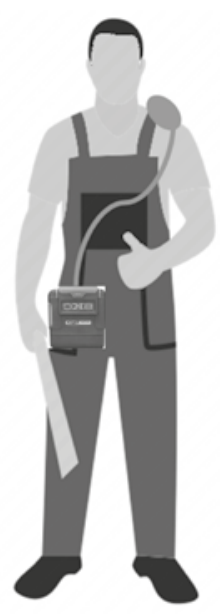

Fig. 1. Scheme of workplace (a) and worker with AirChek (b). 


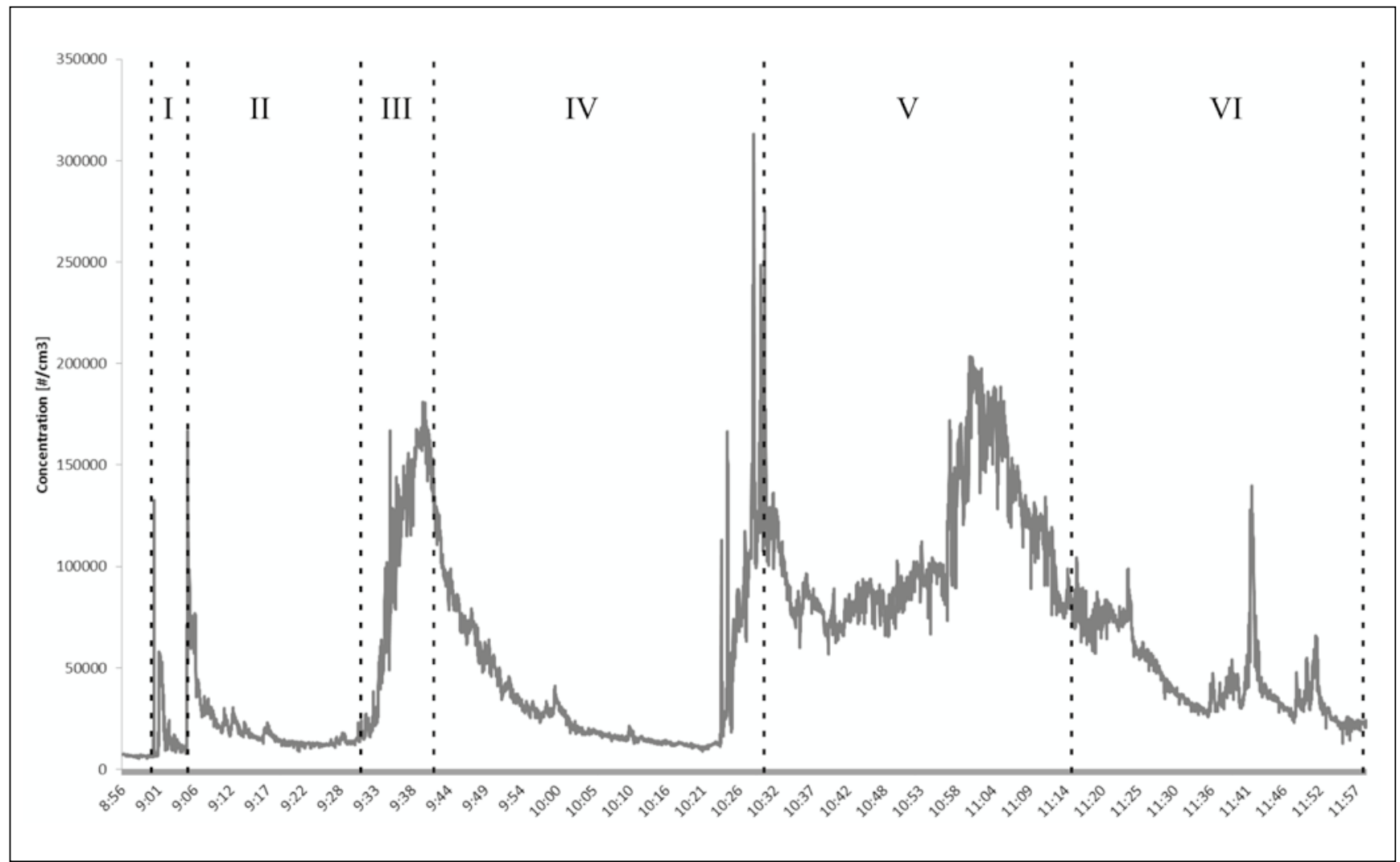

Fig. 2. Records of fine and ultrafine particles concentration development during the staff shift monitoring by TSI CPC 3007. I - grinding, II - welding with ventilation, III - welding without ventilation, IV - welding with ventilation, V - break, VI - welding with ventilation

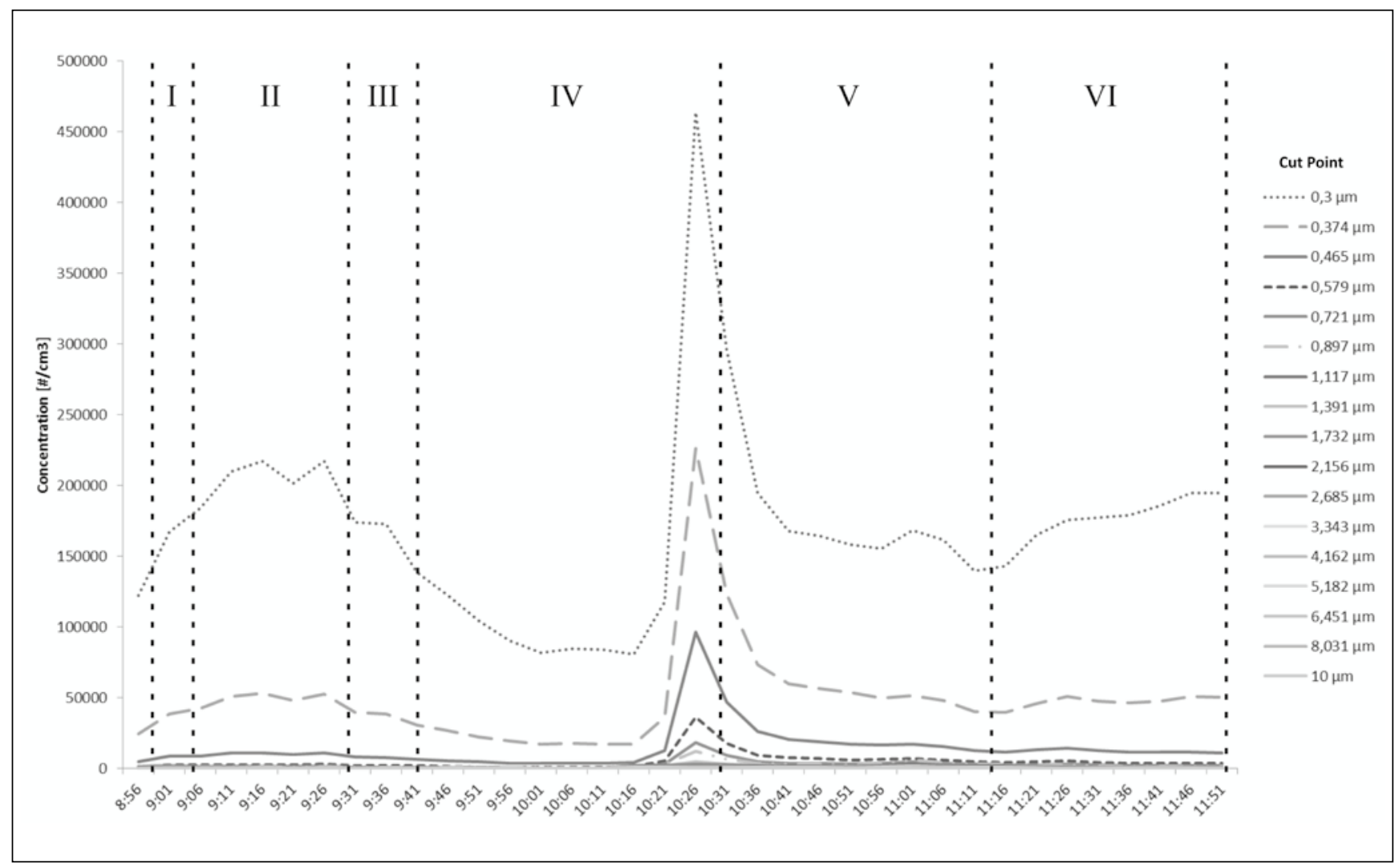

Fig. 3. Records of fine and ultrafine particles concentration development during the staff shift monitoring by TSI OPS 3330(TSI, Ltd.). I - grinding, II - welding with ventilation, III - welding without ventilation, IV - welding with ventilation, V - break, VI - welding with ventilation 

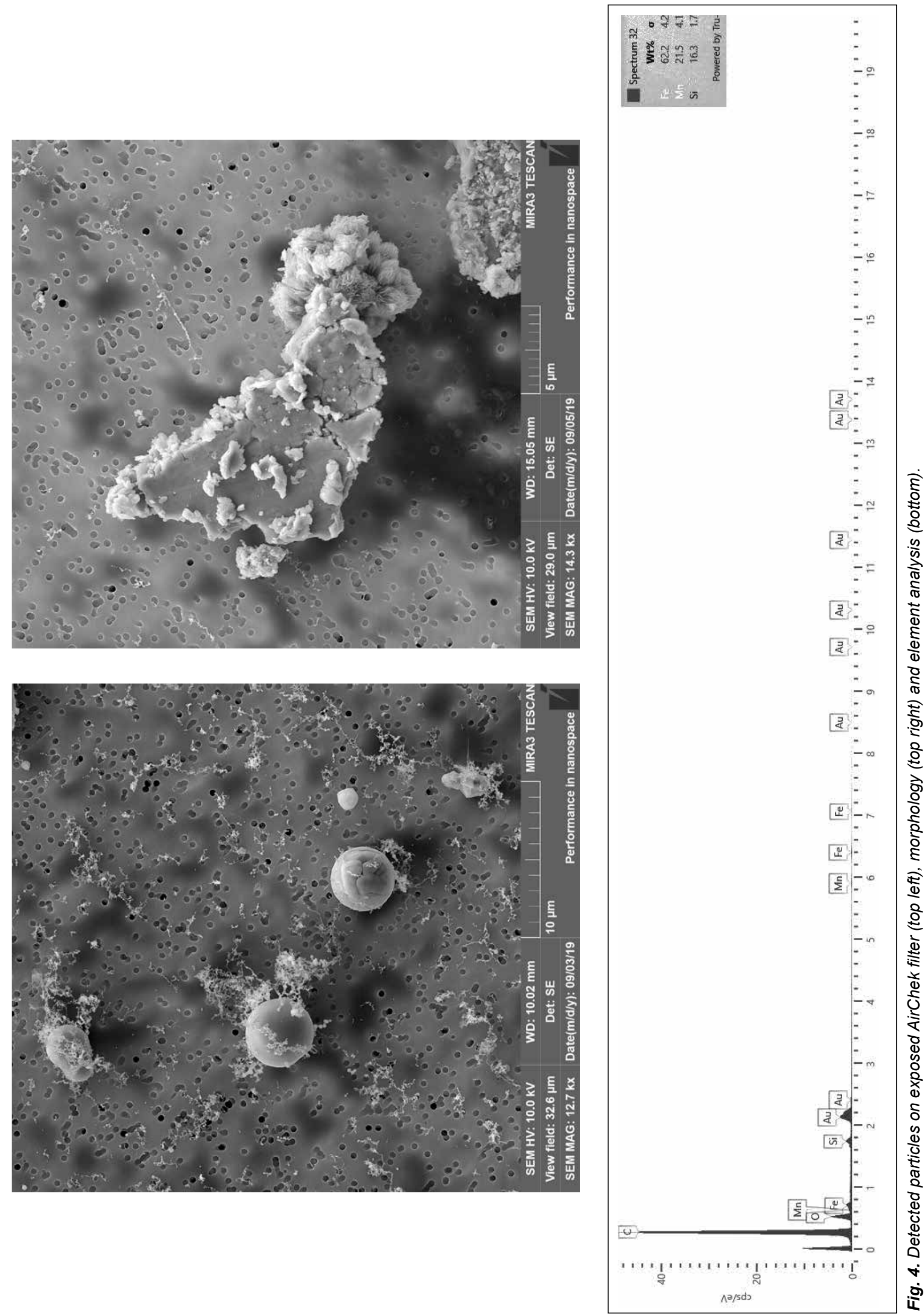

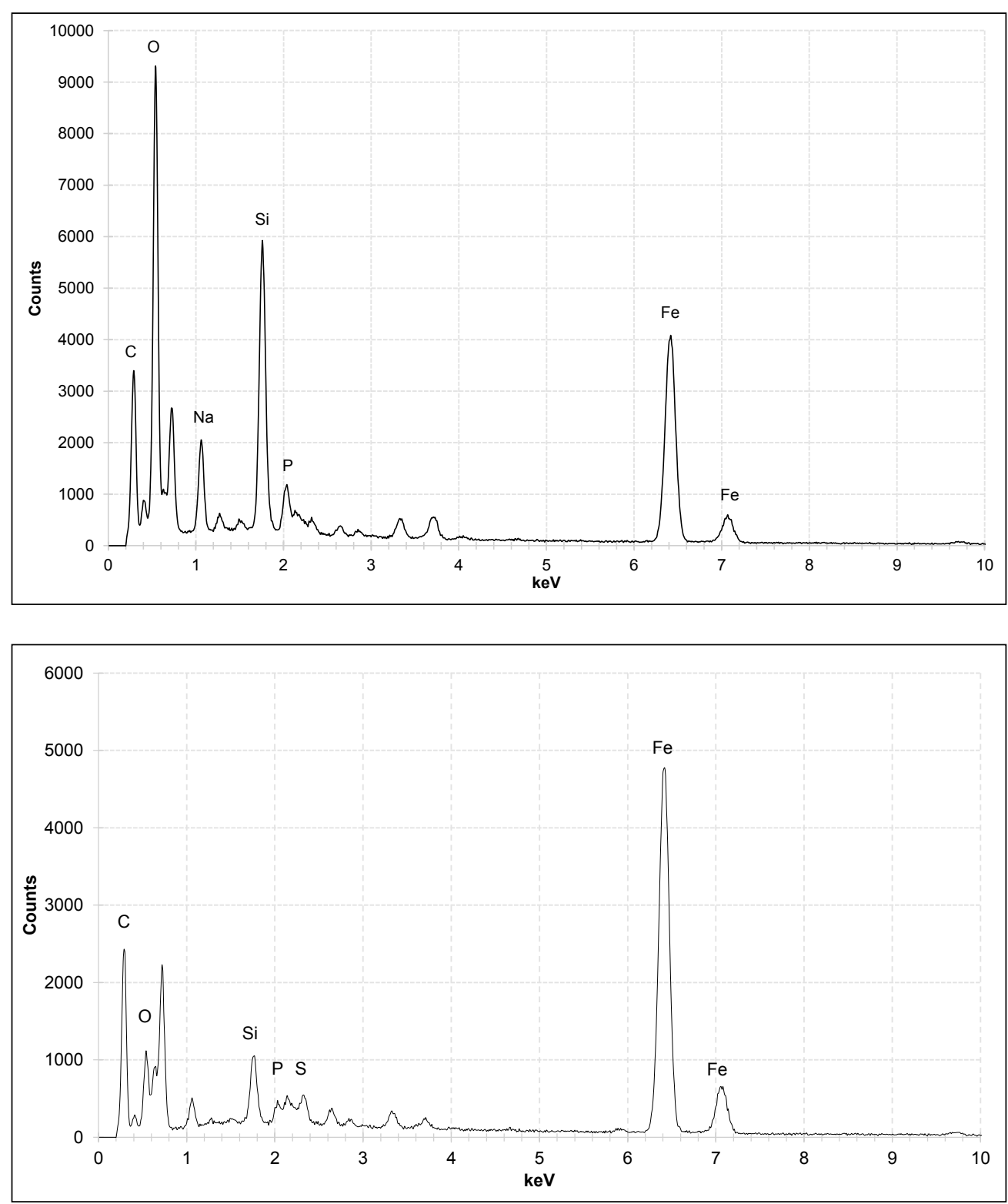

Fig. 5. Detected particles in saliva sample before (top) and after (bottom) of welding process.

Samples of workers saliva $(1 \mathrm{ml})$ were applied in three coats to a slide. Each layer was dry in flow box under germicidal radiation. Prepared samples were sprayed using an SC7620 sprayer and covered with a thin layer of metal. Subsequently, they were analysed by SEM (Quanta FEG 450, FEI), with X-ray microanalysis (EDAX) to determine morphology and elemental particle analysis.

\section{RESULTS AND DISCUSSION}

The obtained results of monitoring show the same trends and the measured data from the CPC, OPS and SidePak correlate with each other at different time intervals. The whole measurement was divided into 6-time intervals according to the work processes: I grinding, II welding with ventilation, III welding without ventilation, IV welding with ventilation, V break, VI welding with ventilation.
From the results of $\mathrm{CPC}$ we can see that at workplace the concentrations of ultrafine particles were minimal prior to welding - around 7,000 particle $/ \mathrm{cm}^{3}$. When the worker started welding (Fig. 2), there was a significant increase in particle concentration in the working environment. At the same time air ventilation was turned on above the welding table. In Figure 2 significant increase and then a decrease in the number of particles can be observed. The particle concentration fluctuated around 13,500 particle $/ \mathrm{cm}^{3}$ throughout the welding process until the ventilation was turned off. The concentration of ultrafine particles increased until ventilation was turned on again. At this time, 10 minutes after the start, the measured number of particles reaches a local maximum, almost tenfold increase in particle. The ventilation was turned off to compare the particle concentration in two conditions - turned on and turned off ventilation. These off/on conditions helped to understand the effect of ventilation on the particle concentration. After the air ventilation is restarted, it is possible to observe 
a gradual decrease in the number of particles up to a steady state, where the particle concentration was similar to the state where the ventilation was turned off. The global maximum particle concentration was recorded at the start of the break at the end of the previous manufacturing process. Immediately after the work was finished, the ventilation was turned off.

From the results of OPS measurements performed at the workplace (Fig. 3), it can be concluded that during welding process particles larger than $800 \mathrm{~nm}$ are formed only in a minimal amount. The highest concentrations were measured for particles $300 \mathrm{~nm}$ and smaller, which are due to their size able to penetrate through the respiratory system deep into the human organism (particles smaller than 1,000 $\mathrm{nm}$ diffuse deep into the lung to the alveolar level), where they may have an adverse effect on the worker's health (9). A trend similar to the results from the CPC instrument can be observed on the curve for $300 \mathrm{~nm}$ particles. The difference from the CPC results is visible in welding without ventilation, where the concentration of particles present decreases. This difference can be caused by observing the different fractions in the two devices.

The results of the workers' saliva and exposed filters analyses by the SEM methods shown the occurrence of elements Fe, Mn and Si particles (Fig. 4 and Fig. 5). The origin of the detected elements is in accordance with the type of welding (electrode $62212 \mathrm{H}$, EN ISO14343-A) and the composition of the welded material (X8CrNi25-21, ISO 1.4845). According to the studies $(10,11)$ increased concentration of these particles in nano dimension may cause neurodegenerative disease or reduction in lung capacity. When comparing the elemental composition of the saliva samples (Fig. 5) obtained before and after welding, a significant increase in the concentration of manganese in the saliva of welders is evident. This increase is most likely due to particles released during welding. At the same time, the particles present in the saliva are in accordance with the composition of the particles captured on the filters. It follows that, in addition to inhalation exposure, oral exposure also occurs.

The obtained results allow for the assessment of a potential human health risk associated with the workers being exposed to fine and ultrafine particulate matter created unintendedly during the welding processes. The efficiency of deposition in the human respiratory tract depends, besides other things, on the size of the particles, when particles of $1-100 \mathrm{~nm}$ deposit the most in the tracheobronchial area (9). Another significant risk is the nanoparticle ability to translocate through the olfactory nerve into the brain structure in a relatively short period of time, where they are also able to deposit (12). Also, the detected elements belong to biologically important elements for human health. However, depending on size and concentration can have toxic effects. There are still many open questions about the health risks of nanoparticles and ultrafine particles to human health (13).

\section{CONCLUSION}

This study deals with exposure of fine and ultrafine particulate matter in work environment. Welding is a process in which nanoparticles are formed as a random by-product. Their shape and composition depend on the type of welding and the material to be welded. The measured results of the concentration of particles in the air of the workplace show that during welding mainly particles with a size of about $300 \mathrm{~nm}$ are produced. The shape of these particles on the filter is mainly irregular. In terms of elemental composition, the analysed particles contained mainly iron, manganese and silicon. These elements are commonly biogenic, but their increased nanoscale concentrations, according to various studies, can have toxic effects. In comparison of samples from saliva and from respiratory tract we can see very similar exposure, so oral exposure should be tested too.

\section{Acknowledgement}

This paper was supported by TA CR within the TL02000240 project of Increasing the Level of OSH Management in Workspace with Occurrence of Fine and Ultrafine particles.

\section{Conflict of Interests}

None declared

\section{REFERENCES}

1. Schulte PA, Geraci CL, Murashov V, Kuempel ED, Zumwalde RD, Castranova $\mathrm{V}$, et al. Occupational safety and health criteria for responsible development of nanotechnology. J Nanopart Res. 2014;16(1):2153. doi: 10.1007/s11051-013-2153-9.

2. van Broekhuizen P, van Broekhuizen F, Cornelissen R, Reijnders L. Workplace exposure to nanoparticles and the application of provisional nanoreference values in times of uncertain risks. J Nanopart Res. 2012;14(4):770. doi: 10.1007/s11051-012-0770-3.

3. Bundschuh M, Filser J, Lüderwald S, McKee MS, Metreveli G, Schaumann GE, et al. Nanoparticles in the environment: where do we come from, where do we go to? Environ Sci Eur. 2018;30(1):6. doi: 10.1186/ s12302-018-0132-6.

4. Pandey RK, Prajapati VK. Molecular and immunological toxic effects of nanoparticles. Int J Biol Macromol. 2018 Feb;107(Pt A):1278-93.

5. Roy R, Kumar S, Tripathi A, Das M, Dwivedi PD. Interactive threats of nanoparticles to the biological system. Immunol Lett. 2014 MarApr;158(1-2):79-87.

6. Regulation (EC) No 1907/2006 of the European Parliament and of the Council of 18 December 2006 concerning the Registration, Evaluation, Authorisation and Restriction of Chemicals (REACH). Off J Eur Union. 2006 Dec 30;49(L 396):1-849.

7. Viitanen AK, Uuksulainen S, Koivisto AJ, Hämeri K, Kauppinen T. Workplace measurements of ultrafine particles - a literature review. Ann Work Expo Health. 2017 Aug 1;61(7):749-58.

8. Pietroiusti A, Magrini A. Engineered nanoparticles at the workplace: current knowledge about workers' risk. Occup Med (Lond). 2014;64(5):319-30.

9. Thomas RJ. Particle size and pathogenicity in the respiratory tract. Virulence. 2013 Nov 15;4(8):847-58.

10. O'Neal SL, Zheng W. Manganese Toxicity upon overexposure: a decade in review. Curr Environ Health Rep. 2015 Sep;2(3):315-28.

11. Murugadoss S, Lison D, Godderis L, Van Den Brule S, Mast J, Brassinne F, et al. Toxicology of silica nanoparticles: an update. Arch Toxicol. 2017 Sep;91(9):2967-3010.

12. Schraufnagel DE. The health effects of ultrafine particles. Exp Mol Med. 2020 Mar;52(3):311-17.

13. Schüllerová B, Adamec V, Bencko V. View to the current developments into the field of nanosafety and risk assessment. Prac Lek. 2019;71(3-4):77-82. (In Czech.)

Received March 13, 2020 Accepted in revised form August 1, 2020 